\title{
Adoption of Project Management Practices in Public Organizations
}

\author{
Panos Fitsilis, Thomas Chalatsis \\ Technological Educational Institute of Thessaly, Business Administration Department, Larissa, Greece \\ Email: Fitsilis@teilar.gr
}

Received 15 July 2014; revised 22 August 2014; accepted 18 September 2014

Copyright (C) 2014 by authors and Scientific Research Publishing Inc.

This work is licensed under the Creative Commons Attribution International License (CC BY). http://creativecommons.org/licenses/by/4.0/

CC) (i) Open Access

\begin{abstract}
The paper studies the adoption of Project Management (PM) practices in Greek public organizations through the study of small-medium Greek Local Governmental Organizations (LGOs). Specifically, it studies how PM practices are applied to small-medium sized LGOs and the factors that are preventing the adoption and the implementation of these PM practices in such organizations. A field study was carried out, using the research methodology of $360^{\circ}$ feedback. More specifically, the views of all different stakeholders were collected and analyzed systematically with the use of semi-structured interviews. The conclusions of this work are that the factors which are blocking the implementation of a PM system, in a small-medium LGO, are grouped in two categories: the factors that are related with the adjustments of the standards to the structure of the LGOs and the inhibiting factors of the internal environment of the LGOs (concerning project management).
\end{abstract}

\section{Keywords}

Project Management, Project Management Maturity Models, Public Management

\section{Introduction}

Globally, projects managed by public organizations exhibit increased complexity in comparison to those managed by private companies [1]. This conclusion is not different in Greek public-sector. According to the Management and Organization Unit (MOU) of Community Support Framework (CSF) for Greece [2], the majority of Greek public organizations did not implement modern project management practices, tools and methodologies. A possible solution for the improvement of project management capability of public organizations is the adoption and the implementation of a Project Management Capability Model (PMCM). A PMCM is defined as the description of the processes which are implemented by an organization, to assure and upgrade its project management capability [3]. A typical PMCM includes documented processes, a system manual, a set of standar- 
dized documents and standardized files and work instructions, which are documenting the project management processes of an organization, on every phase of a project cycle.

The current study was conducted on Local Governmental Organizations (LGO) of the Greek Public Sector. An LGO constitutes the first degree of the Greek Governance System. Their main responsibility is the promotion of the local development. Therefore, they implement mainly construction projects, such as roads, environmental infrastructure, sports facilities, water and power supplies and improvement of public areas. Also, LGOs implement projects of social context, IT projects and projects concerning the protection of public health. The Greek Company for Local Development and Governance [4] classifies Greek LGOs into four categories: Large, Medium-Large, Small-Medium and Small. The criteria used for this categorization are the number of employees, the population size and the annual income [5]. The small-medium LGOs are the majority, as they represent the 43\% of all Greek LGOs (143 from 325), with an average population of 19,187 individuals and approximately 90 staff members on average. After a recent restructuring of the Greek Governance Architecture [6], LGOs have increased needs for management skills, because of: 1) their augmented responsibilities and 2) the limited funding from the central government. At the same time, due to the relevant statutory requirement, LGOs have already developed PMCMs, in order to obtain permission to undertake projects, financed by the Greek National Strategic Reference Framework (NSRF). Taking into account the above described facts, it becomes evident that smallmedium LGOs are the most suitable candidate organizations both for examining how a PMCM system is applied on Greek public organizations and as well for identifying the factors, which are blocking the effectiveness of PMCM models, when applied to public organizations.

The main objective of this article is the identification of the critical factors, which are limiting the application of a PMCM in a small-medium Greek LGO, either produced from the internal environment or attributed to the external environment.

The organization of this paper is as follows. In Section 2 the literature review is presented. This is followed by Section 3 addressing the research methodology, Section 4 presenting the research results and Section 5 that provides the conclusions.

\section{Literature Review}

Every project—even the smallest one-goes through similar series of stages, beginning with the initiation stage and ending when the project handed over. This flow is called project life cycle [7]. Each project life cycle phase is implemented through a set of project management processes, processes that are interrelated and dependent to each other, forming project management processes groups [8].

At the same time, a project is always carried out within the framework of an organization [9], so for its success, it should be aligned to the strategic objectives and the special characteristics of this organization [10]. The standardization of the project processes and their integration in the working-routine of the organization, are able to bring significant advantages to the organization, like, elimination of internal conflicts, acceleration of the project implementation and improvement of the financial results [11]. On this basis, organizations realized the need for systematic management of projects that lead gradually to the development of Project Management and Project Management Capability/Maturity Standards [12]-[17].

\subsection{Theoretical Perspective and Reflection}

A critical question about the examined subject is if the standardization of the project management processes is the proper way for improving the managerial capability of LGOs in Greece. Many researchers present arguments that "standardization" is not always the solution for every organizational problem. Vardakas [18] claims that the standardization of the project management processes inhibits innovation spirit, since the strict framework of a PMCM prevents the development of new ideas and initiatives.

The well-known study of Lawrence and Lorsch [19] on the relationship between the external environment of an organization and the most effective organizational strategy revolves between the concepts of "integration" and "differentiation". Integration is defined as the process of achieving unity of effort amongst various subsystems of an organization, while differentiation is a state of segmentation of the organization into subsystems each of which develop different strategy in relationship to the demands defined by the external environment.

Lawrence and Lorsch, through a field study, tested the connection between differentiation, integration and organizational performance in complex organizations. The authors identified it as a factor of great importance, the 
"requisite integration". The requisite integration is defined as the degree whether the characteristics of the tasks of an organization allow the subsystems to operate independently. They concluded that if requisite integration existed in an organization (independent subsystems), then it was more difficult to achieve integration. Extending this point, we can conclude that if the requisite integration is low (the subsystems of the organization have to collaborate strongly, during their operation, to achieve results), the most advisable strategy for an organization to improve its organizational performance is integration.

Adjusting the above views to a small-medium Greek LGO, we can infer that the adoption of a PM standard is the appropriate strategy to upgrade project management capability. More specifically, departments of Greek LGOs are characterized by low requisite integration, since their operation involves strong collaboration, through integrative devices (like coordination bodies or common structures).

\subsection{Managing Projects of Public Interest in Greece}

European Union uses large-scale fiscal transfers to national and regional levels to foster economic and social cohesion [20]. Over the last two decades, structural fund programmes supported by the European Union have operated at the level of Member States and regions aiming at providing growth. Some figures concerning the last support framework programme of Greece that run during the period starting from 2000 to 2006 are indicative of the size and the complexity of the programme: 13,427 projects were funded, average project budget 1.8 million Euro, and total number of beneficiaries 2748. This gives an average of less than five projects per beneficiary. It should be noted that most beneficiaries were large public organizations such as ministries, universities, LGOs, etc.

According to a study conducted by the Management Organization Unit (MOU) of Community Support Framework (CSF) on the managerial capability of the beneficiaries [2], it was made clear that a large number of organizations, approximately $22 \%$ were not capable of managing projects and an even larger percentage ranging from $30 \%$ to $65 \%$, depending on the criteria applied, was not using modern or efficient project management practices. The inability of public organizations to effectively deliver projects is not a local phenomenon but it occurs in many countries, especially the developing ones [21] [22].

Some of the reasons that contribute to project management lack of maturity [2] were identified as: 1) Lack of formally defined processes or of a defined quality management system; 2) Unavailability of internal auditing and review procedures; 3) Loose project schedule control, lack of modern project management information systems, unavailability of legal support in a rather complex legal and contractual context, etc.

In order to analyze the managerial capability of the Greek public organizations, it is important to study the dimensions of the Greek cultural environment, since management of organizations cannot be isolated from their culture environment.

Through the review of the relevant literature, we can detect several cultural differences which affect Greek organizations' culture. The most ambitious effort to study—in quantitative terms - the culture dimensions and their connections with the organizational culture and organizational leadership was GLOBE-Project [23]. In this project, an evaluation was carried out, on the effects of basic cultural dimensions on organizational culture, in selected countries. Some of the key cultural dimensions were: future orientation (degree to which individuals in organizations or societies engage in future-oriented behaviors), individualism-collectivism (the degree to which individuals are integrated into groups within a collective) and performance orientation (the extent to which an organization or society encourages and rewards group members for performance improvement and excellence) [24].

The findings of GLOBE-Project highlighted some important aspects, affecting directly the managerial capability of the Greek public sector. In specific, Greece is ranked with the lower score among European countries on the cultural dimension of collectivism, thus the collaboration and the involvement of the basic stakeholders-the key factor for successful management of public projects-is inevitably low. In addition, Greece is within the group of European countries with the lowest score on the cultural dimension of "future orientation", so long-term planning skills (critical factor for the project management capability of an organization) are not considered strong within the Greek public sector. Finally, Greece is the lowest in the rank, on the dimension of performance orientation, therefore procedures like internal audits and schedule and budget controls are not included in the working-routine of the Greek public organizations. Naturally, the cultural dimensions are not the only factor affecting the efficiency of project management in Greece, however, some of the observed deficien- 
cies could easily be attributed to the cultural profile of Greece.

\subsection{Greek PM Standard ELOT 1429:2008}

In order to tackle the above-described cultural barriers and at the same time to improve the performance of organizations that undertake projects of public interest, it has been decided by the Ministry of Economy and Finance (ministerial decision published in the Official Journal of the Hellenic Government part B 55/18.1.2008) to develop a new national standard, named "ELOT 1429:2008", that will define the requirements and capabilities needed by organizations implementing projects of public interest. Moreover, Greek Law 3614/2007 states that organizations wishing to implement projects funded by CSF will have to comply with this standard. The certificate of compliance with the new PM Standard would be the prerequisite for an organization, in order to undertake a co-financed by European Union project. This certificate would be provided by licensed organizations, after a detailed review, both of the developed PMCM and of the general project management efficiency, of the assessed organization. Obviously, the application of the standard will assist organizations undertaking projects of public interest to improve their managerial capability and, at the same time, it will offer a focal point of reference for assessing an organization's maturity and performance [25].

Although there were available both project management standards and managerial capability models for project management at either international level or national level (in other European Union countries), the Hellenic Organization for Standardization (ELOT) decided not to adopt a standard but to develop a new one.

The development of ELOT 1429:2008 standard took into account the following [25]:

- PM standards about project management capability like, OPM3 [18], P3M3 [26], CMMI [17].

- Project Management bodies of knowledge or efficiency, such as PMBOK [27] and ICB [28].

- International technical specifications, guides, good practices, such as "Good practices for the management of public contracts of Cypriot Democracy” [29], ISO 1006 [30], "Guide for project’s success” by New York State [31], etc.

Concerning the structure of ELOT 1429:2008 [3], it consists of 8 chapters. The first three have introductory type (introduction, references, dictionary, main definitions) while the remaining chapters present the requirements, which must be satisfied by a PMCM. In addition, they are two annexes, which contain references and the dictionary of terms.

In ELOT 1429:2008, organizations are classified on the basis of their project management maturity level. The standard defines three levels of project management maturity: at first level, organizations are able to carry out projects, using their own processes, satisfying default settings, at the second level, organizations are managing their projects in a standard way, using project central administration, while at the third level, organizations are monitoring - in quantitative terms-the processes' implementation and they are improving the system-according to the findings - on a regular basis. This classification is justified by the low current project management maturity level of the Greek public organizations. Specifically, a three-scale model was considered as more feasible for these organizations, since it will allow organizations to introduce PM practices gradually and stepwise.

\subsection{Inhibiting Factors}

The factors affecting the implementation of PMCM in a Greek LGO can be classified into two main categories, the inhibiting factors, derived from the internal environment of LGOs (concerning project management) and the problems which occur during the adjustment of a PM standard to a small-medium LGO.

\subsubsection{Inhibiting Factors Derived from the Internal Environment}

These factors are linked with the internal environment of the LGOs and they affect their project management capability. The factors of this category do not relate directly with PMCM but they are crucial for the proper implementation in a LGO. The examined factors here were:

- Inadequate staff: According to the literature review, the number of the competent-for the project management activities-available employees in LGO organizations is not sufficient. Consequently, the projects of these organizations face increased problems and this weakness seems to be more intense in small-medium LGOs [32]. In this conclusion converged many researches, such as Pateraki [33], Information-TrainingLocal Development S.A. (2008) and Local Governance Institute (2005), placing the problem of inadequate 
staff, in the general problem of the lack of resources, afflicting the small-medium LGOs in Greece.

- Unequal distribution of workload: In many cases, the departments of LGOs, which are involved in the project management, are facing unequal workload. A relevant study of PETA [34] has demonstrated also, unequal workload within the "core business" departments, as the workload is not balanced and therefore some employees undertake heavier workload, in comparison with others, leading to resource levelling problems. A relative problem is that-according to MOU [2]—-the employees of LGOs have not defined work responsibilities that are necessary in a typical bureaucratic organization. As a result, the staff of these departments has to deal with a large number of different work subjects, a factor that leads to disorientation and low productivity.

- Lack of specialized departments: A common conclusion extracted from the literature review was that many specialized units, such as IT, project planning or legal departments do not operate in small-medium LGOs, despite the fact that they were described in their organization chart. In these cases, the responsibility was assigned either to an employee or it was outsourced. On the other hand, these departments are considered by MOU [2] as indispensable for the project management effectiveness of an organization. A similar assessment of the situation was also presented by Papadakis [35].

The above-mentioned factors were evaluated by the participants of the research, both concerning their occurrence frequency and their importance weight. At this point, it should be noted that factors such as, the experience of the employees or the level of stakeholders' involvement were not examined in this research, as they were not documented in relevant studies or researches.

\subsubsection{Inhibiting Factors Related with the Adjustment of a PMCM to a Small-Medium LGO}

These factors are related with the used PM standards and their application to the regulatory environment (certification process, relevant legislation) and also they are couples with the requirements of a PMCM and the compatibility of these requirements with the internal environment (work-routine, organizational and administrative features). For this research question, 12 factors were examined:

- Incomprehensible documentation: The comprehensible documentation of the PMCM (system manuals, technical specifications, written processes) is considered as prerequisite for the success of a PMCM, since documentation provides a "mean of communication" within the system. It is evident that comprehensible documentation leads to successful implementation of a PMCM [36].

- Lack of commitment by the management of the LGOs: One conclusion derived from literature review, was that strong commitment manifested by the management of an organization and moreover its constant effort for the implementation of the PMCM model is considered as a critical factor [37].

- Insufficient academic/professional qualifications of the staff in relation with project management: Related studies indicated that the academic/professional qualifications of the technical staff in Greece, concerning project management, are not considered sufficient/adequate. More specifically, these studies revealed knowledge gaps in various phases of the project life cycle, e.g. project planning, requirements specifications [38], but as well lack of general knowledge of project management [39].

- Deficient coordination of the involved departments: According to Papatheodorou [40], the experience acquired by the evaluation of PMCMs of small-medium LGOs, indicated as inhibiting factor, the defective coordination between the involved departments. The appearance of this factor at small-medium LGOs was also confirmed by the studies of [4] and ITA (2006).

- Inability to implement special requirements of a PMCM: The implementation of PMCMs, involves the definition of competencies, internal and external controls and standardization of internal processes. The employees of LGOs do not possess the specialized know-how and skills, needed to satisfy these requirements and as result, the entire process of introducing the PMCM in these organizations, is complicated [40].

- Incompatibilities of PMCM with work practice of LGOs: Certain aspects of PMCMs, such as, the detailed archiving, the strong commitment to the compliance with the written processes and the documentation, are not compatible with the routine of LGOs [41].

- Cautious attitude by the staff: This is a common problem to business re-engineering projects (such as the development and implementation of a PMCM), since employees are concerned with layoffs or decrease of their remuneration, due to redesigned processes and the standardization of the work-routine [42]. This factor, according to Papatheodorou [40], was encountered in the case of small-medium LGOs, through the refusal of the staff to transfer and document its experience as needed by the introduction of PMCM or through the mi- 
nimal contribution to the development of the system.

- Gap between the daily practice and the documented processes: The PMCM is introducing additional requirements to the already existing daily practices (e.g. existence of competent staff, internal controls, correction of non-compliances), which the management and personnel of LGOs is difficult or impossible to meet [40].

- Inappropriate PM standards: The standards which were used as the base of PMCMs in Greek LGOs were characterized as bureaucratic, too formal, time-consuming, inflexible and generally not in-line with the daily work practice.

- Problems related to the outsourcing of the PMCM development process: In the majority of small-medium LGOs, the development of the PMCM was outsourced to external consultants and as a consequence, LGOs' employees were not sufficiently involved in this process. In many cases, this factor resulted to the inability of the employees, to understand and finally to implement the developed PMCM [40].

- Insufficient support by the central government: The development and the implementation of PMCMs in LGOs is a complex undertaking, which requires constant support by the central government (like help-desks, information campaign and rapid response to the problems). Lack of support is-according to the relevant study of PETA [34] — turned out to be a major problem for the proper implementation of the systems, in these organizations.

- Impedance of LGOs for reengineering and changing their work practices: The development of the PMCM is a process, where the project management processes of an organization are reengineered [43]. In general, public organizations in Greece are structures regulated by national legislation and as a result, organizational changes require adaption of legislation. Therefore, the introduction of PMCM in LGOs has to face in many cases legislative obstacles.

\section{Research Methodology}

The objective of this work is the identification of the main factors, which are restricting the engagement and the implementation of a PMCM, in a small-medium Greek LGO. The factors affecting the implementation of PMCM in a Greek LGO were classified into two main categories, the inhibiting factors, derived from the internal environment of LGOs (concerning project management) and the problems which occur during the adjustment of a PM standard to a small-medium LGO. The two research questions explicitly stated are:

Research Question 1: Which are the inhibiting factors to the introduction of a PMCM system related with the internal environment?

Research Question 2: Which are the inhibiting factors related with the adjustment of a PMCM to a smallmedium LGO?

This research is by definition exploratory, since 1) the factors that may influence the adoption of a PMCM can vary considerably; 2) these factors are influenced by the internal environment of the LGOs; 3) the external environment of LGOs varies considerably and 4) the available organizations, satisfying specific characteristics, and introducing a PMCM system within the time frame of the study was extremely low. Since this study is purely qualitative and exploratory, statistical analysis of the obtained data is not recommended, because statistical methods like ANOVA usually require five samples per category [44], constraint that it is not satisfied in this study. Wherever an average score is presented this is purely presented to indicate the trend and not for establishing a relationship or for proving a hypothesis. In our research, we have selected to use a "360 degree feedback" research methodology, since this methodology allows the extraction of the opinions and the views of every stakeholder involved on the topic under investigation [45]. The origins of this methodology are located in the scientific field of the human resources, where the performance of the employee is evaluated not only by his superiors, but by every person involved in his working routine, like colleagues, clients, suppliers [46]. Respectively, in this research, the "360 degree feedback" research methodology was complemented with in-depth interviews that were based on semi-structured questionnaires, in order to increase as much as possible the validity of the results.

On this base, during the field study, they were conducted 16 interviews with representatives of the following stakeholders groups:

- Employees of four small-medium LGOs, who were involved in the development procedure of the PMCM in their organizations. The profile of those employees was mainly technical since most of them were involved with construction projects that constitute the majority of the projects of LGOs. 
- Technical consultants, who provided technical support to LGOs, for developing the PMCMs. This group of participants had quite diverse academic and professional background since the development of an LGO requires management, legal but as well, technical skills.

- Reviewers (evaluators) of the PMCM system, who evaluated the developed system, members of the administrative authority responsible for conducting the final assessment and for giving the certification.

Every participated group contributed to the study, through its special knowledge and experience. In particular, the employees have experience, acquired by the daily implementation/application of the project management processes within the LGOs and additionally they have been actively involved in the development of the PMCM in their organization. On the contrary, their experience and knowledge level on PM Standards and the generic requirements needed were limited, since they had been involved in the development process, usually within a single organization.

Technical consultants are familiar both with the adjustment process in numerous organizations and with PM standards, as well as with the requirements of the certification process. On the other hand, members of this group usually do not participate in the actual implementation of such systems.

Finally, reviewers are not experienced with project management processes and the work-routine within an LGO and as well they did not follow the development process of the PMCM in these organizations. However, the representatives of this group have acquired significant experience on the implementation of PMCMs and on the problems encountered during review process, as they have examined in detail, numerous PMCMs, developed by various LGOs.

Having identified these differences in these diverse stakeholder groups, a different questionnaire structure and as well a different set of questions were used in the interviews of every stakeholders group, based on their characteristics. The questionnaires contained a mix of forced choice responses (a set of alternative responses was provided for every question) and open-ended questions (the participants were free to express their own view). In the forced-choice responses, in order to evaluate the views expressed by the stakeholders, it 5-point Likert rating scale was used [47].

\section{Discussion and Results}

\subsection{Results}

The inhibiting factors, used as the basis for the interviews, were extracted from the literature review, conducted prior to the study. The aim was to examine both the occurrence frequency and the importance level, of every factor, which, according to the relevant literature, affects the proper implementation of a PMCM.

Research Question 1: The main conclusion extracted from this research question is that there are two main factors, derived from the internal environment of an LGO, which have a negative impact on the proper implementation of PMCMs. In particular, the unequal distribution of workload within the "core business" departments was considered by the interviewees, as the most negative factor in this category, with convergent of opinions between the stakeholders groups. An interesting point made by the interviewees concerning this factor was that technical departments undertake "heavier" workload, in comparison with planning or administrative departments, because apart from the project management, they are responsible for numerous work activities, such as the assistance of the elected bodies and work related with technical issues (buildings permits, urban plans, technical audits etc.). According to the participants, in many cases, this overload is the "source" for failures and delays in the management of projects by LGOs.

Additionally, the findings derived from studies and researches regarding project management in Greek LGOs, like those of PETA [34], ITA [48] and MOU [2], indicated as well that knowledgeable and competent personnel in the "core business" departments is a primary stress point. However, as the participants highlighted, this issue should be examined in "qualitative terms", since in the majority of LGOs the number of employees was considered, as sufficient but on the other hand, the scientific background, the professional qualifications and their competences of the personnel were considered as inadequate. Particularly, there is lack of professionals, like engineers, lawyers, IT experts and accountants while there is surplus of low-qualified professions, such as ushers, laborers and auxiliary staff.

Research Question 2: In Table 1, the evaluation of each factor according to the participants of this study is presented. Further, the frequency of occurrence for each factor and its impact weight is presented. 
Table 1. Evaluation of inhibiting factors for the introduction of PMCM (average scores).

\begin{tabular}{|c|c|c|c|c|c|c|c|c|}
\hline EXAMINED FACTOR & \multicolumn{2}{|c|}{ EMPLOYEE } & \multicolumn{2}{|c|}{ REVIEWERS } & \multicolumn{2}{|c|}{ CONSULTANTS } & \multicolumn{2}{|c|}{ TOTAL } \\
\hline$F=$ Frequency of occurrence $W=$ Impact weighting & $\mathbf{F}$ & W & $\mathbf{F}$ & W & $\mathbf{F}$ & $\mathbf{W}$ & $\mathbf{F}$ & $\mathbf{W}$ \\
\hline Incomprehensible documentation & 2.1 & 4.6 & 3.5 & 4.3 & & & 2.8 & 4.4 \\
\hline Lack of commitment by the management of the LGOs & 3.3 & 4.6 & 3.8 & 4.8 & 3.0 & 4.6 & 3.4 & 4.7 \\
\hline Incompatibilities with the work practice & 2.9 & 3.6 & 2.8 & 4.8 & & & 2.9 & 4.2 \\
\hline $\begin{array}{l}\text { Insufficient academic/professional qualifications of } \\
\text { the employees in relation with project management }\end{array}$ & 3.0 & 3.4 & 3.8 & 4.8 & 3.8 & 3.6 & 3.5 & 3.9 \\
\hline Deficient coordination of the involved departments & 3.0 & 2.7 & 3.2 & 3.5 & 4.2 & 4.4 & 3.5 & 3.5 \\
\hline Cautious attitude by the employees & & & 3.8 & 3.0 & 3.8 & 3.2 & 3.8 & 3.1 \\
\hline Inability to implement special requirements of a PMCM & 2.1 & 2.4 & 2.8 & 3.8 & 3.2 & 2.4 & 2.7 & 2.9 \\
\hline $\begin{array}{l}\text { Problems related to the outsourcing of } \\
\text { the PMCM development process }\end{array}$ & 2.4 & 3.0 & 3.8 & 4.0 & 3.4 & 3.8 & 3.2 & 3.6 \\
\hline $\begin{array}{l}\text { Gap between the daily practice and } \\
\text { the documented processes }\end{array}$ & 3.6 & 3.7 & 2.5 & 2.0 & 2.0 & 2.0 & 2.7 & 2.6 \\
\hline $\begin{array}{l}\text { Impedance of LGOs for reengineering and } \\
\text { changing their work practices }\end{array}$ & 2.9 & 3.6 & 2.8 & 2.5 & 3.4 & 3.2 & 3.0 & 3.1 \\
\hline Insufficient support by the Central Government & 2.3 & 2.4 & 2.0 & 2.3 & 3.0 & 2.4 & 2.4 & 2.4 \\
\hline Inappropriate PM standards & 1.7 & 1.4 & 1.8 & 3.5 & 2.2 & 2.2 & 1.9 & 2.4 \\
\hline
\end{tabular}

Considering the results of the evaluation, the most important inhibiting factor for the proper implementation of a PMCM in a small-medium LGO, is insufficient academic/professional qualifications of the staff on project management. This factor was examined in particular, during the field study, since the available curriculum offered by Greek universities, on project management, are limited. A relevant study [39], on graduates of Technical Universities in Greece revealed that a significant part, in specific 37\%, considered that the education they received on project management was insufficient. Kalofolias [22] confirmed these findings, adding that several phases of project life cycle are not taught at the Greek higher education (e.g., procurement processes, account management). Taking these into account, the interviewees were asked to evaluate the educational level of the staff of LGOs on nine knowledge areas, as they are defined in PMBOK [27]. The findings confirmed the results of the literature, since participants evaluated the knowledge level of the staff in relation to project management, as very low. Indeed, in some knowledge areas, such as, scope management and risk management, the level of knowledge of the staff was judged as completely inadequate. It is interesting that in this question, the staff who participated in this research, evaluated its own level of knowledge, as very low and alongside the same participants evaluated this, as critical factor for the proper implementation of the PMCM. The findings are presented in Table 2.

Another inhibiting factor that was considered important by the participants of this study was insufficient collaboration/coordination between the involved departments. This factor was detected in a series of studies with regard to project management capability of Greek LGOs. In the "Guide for the adjustment of the organizational charts of LGOs" [5], it is presented that in every work-process of an LGO, where they are involved more than one organizational unit (such as the project management), conflicts and misunderstandings arise, due to the lack of coordination. The defective coordination between the departments is mentioned also by EETAA [4] and Papatheodorou [40].

Another inhibiting factor that was identified was the lack of commitment by the management of LGOs. The importance of management commitment is common factor that has been identified in numerous studies [34] [37]. The results of the field study were in accordance with the findings of other similar studies, both concerning the frequency of occurrence and the weighting of impact. Further, a common view expressed by interviewees was that it is indispensable for the success of a PMCM, the implementation of training (seminars, working meetings). 
Table 2. Evaluation of the level of knowledge of LGO employees on PM areas of knowledge.

\begin{tabular}{cccc}
\hline PM AREA OF KNOWLEDGE & EMPLOYEES & REVIEWERS & CONSULTANTS \\
\hline Project Risk Management & 1.71 & 1.25 & 1.2 \\
Project Procurement Management & 1.85 & 2.25 & 2 \\
Project Integration Management & 1.71 & 1.5 & 1.8 \\
Project Scope Management & 1.42 & 1.25 & 2.6 \\
Project Time Management & 2.85 & 3.5 & 2.8 \\
Project Cost Management & 2.85 & 2.75 & 1.6 \\
Project Quality Management & 2.57 & 1.25 & 1.4 \\
Project Human Resource Management & 2 & 1.75 & 2 \\
Project Communications Management & 2 & 2 & \\
\hline
\end{tabular}

Scale 1-5 (5-maximum educational level - 1 minimum).

Finally, the cautious attitude by the staff was also considered as a very important factor by the participants, confirming the relevant literature [40]. The consultants mentioned here, that this cautiousness was expressed in practice, through the refusal of the employees to contribute to the development of the PMCM. Specifically, all consultants claimed that employees were negative in participating in the working meetings or they did not provide necessary data or documents. The underlying causes for this attitude, according to the consultants, are both that employees of LGOs considered the PMCM as an extra effort imposed by the central government without any practical usefulness and that the implementation of a PMCM will inevitably cause changes in their workroutine.

\subsection{Main Suggestions/Proposals Made by Participants of This Study}

During the interviews the participants were asked to propose measures, which could facilitate the proper implementation of PMCM in a Greek LGO. This question was open-ended and the interviewees were able to express their own views. The proposals tabled could be summarized in below:

- Connection of PMCM with the evaluation: Through the study it was indicated that there was lack of commitment for the implementation of PMCMs expressed both by the staff and the Head of LGOs. In order to counter this factor, a measure proposed by interviewees was the connection of the implementation of PMCMs with the performance evaluation system. According to the Greek Law (L.3839/2010) [17], the performance of public servants in Greece is evaluated through a point-system. This point-system is used for the selection of the directors and generally for the status of every employee. The integration of PMCM in this point-system could motivate the staff of LGOs to implement the system. Simultaneously, through the Law 3230/2004 [49], they are established the "National Awards for Quality Public Services". In specific, annually, the Greek public services which succeeded their goals or carried out innovative actions and initiatives are awarded. The addition of a special section about PMCMs in these awards could be really helpful for the motivation of the staff and the Head of LGOs, in order to implement PMCMs.

- Development of PM training packages: The study shows that the staff of LGOs has not adequate knowledge about PMCMs and generally about project management issues. On this basis, the development of relevant educational packages by central government and their distribution to the competent staff of LGOs could bring positive results. The use of e-learning applications and the establishment of minimum number of educational actions, which every employee of LGO have to attend annually, suggested by the participants to enhance the effectiveness of this measure.

\section{Conclusions}

In the present case study, the PMCM implementation at the Greek public organizations was studied. In these organizations, the demand for advanced project management capability is rapidly increasing, but in the same time, 
their project management capability remains low. Therefore, the implementation of a PMCM is considered as a vital priority for these organizations.

According to the findings of the study and in line with the findings of other similar studies, the most important factors that are inhibiting the introduction of PMCM in small and medium size LGOs are: 1) insufficient knowledge and qualifications of the staff on project management subject areas; 2) insufficient communication and coordination between related departments because of the hierarchical structure of Greek LGOs; 3) lack of management commitment throughout the development and the application of the PMCM and 4) the cautious approach taken by members of the staff because of the radical changes introduced.

The main conclusions of this paper are that PMCMs are able to upgrade the project management capability of the public organizations in Greece, only if the following prerequisites are satisfied:

- Both the management and the personnel of these organizations will demonstrate strong commitment and promptness towards the implementation and the constant improvement of PMCMs. The commitment indicated by the field study and the relative literature as indispensable factor for the implementation of PMCM in a small-medium LGO.

- Development of training packages and implementation of educational actions (seminars, conferences) about PMCMs and project management by Central Government.

Regarding the future research directions of the examined topic, the point detected in this study which could be a matter of further research, is the educational level of the staff of Greek LGOs, concerning project management. In specific, the study indicated that the employees of Greek LGOs, responsible for the project management of these organizations, have not satisfying knowledge level about specific areas of project management scientific field, such as scope and risk management. A really challenging task could be a detailed research concerning the current educational level of LGOs staff, the educational needs and appropriate measures capable to fill the existing educational gaps on specific project management fields.

\section{References}

[1] Weinstein, J. and Jackques, T. (2010) Achieving Project Management in the Federal Government. Management Concepts Inc., Vienna, VA.

[2] Management Organization Unit (MOU) of Community Support Framework (2005) Study on the Managerial Capability of Organizations Implementing Projects of Public Interest. Athens. http://www.mou.gr/index.asp?a_id=385

[3] ELOT 1429 (2008) Project Management Capability of Organizations about the Management of Projects of Public Interest. Hellenic Organization for Standardization, Athens.

[4] EETAA (2008) Manual for System for the Certification of the Project Management Capability of Local Government for the Period 2007-2013. Greek Company for Local Development and Governance-EETAA, Athens. http://www.eetaa.gr:8080/efd/show_thesmiko.jsp?thes_code=3

[5] EETAA (2010) Guide for the Adjustment of Organizational Charts of LGOs. Greek Company for Local Development and Governance-EETAA, Athens. http://www.eetaa.gr:8080/kallikratis/support/odhgoi.jsp

[6] Greek Official Journal (2010) Law 3852/2010 New Architecture of the Governance and Decentralized AdministrationProject Kallikratis. Office of Publications, Athens. http://www.et.gr

[7] Harrison, F. and Lock, D. (2004) Advanced Project Management: A Structured Approach. 4th Edition, Gower Publishing Limited, Aldershot, 80.

[8] Heldman, K. and Mangano, V. (2009) PMP: Project Management Professional Exams Review Guide. Wiley Publishing Inc., Hoboken, 15.

[9] Pharro, R. and Bentley, C. (2007) Processes and Procedures. In: Turner, J.R., Ed., Handbook of Project Management, 4th Edition, Gower Publishing Limited, Aldershot, 127-152.

[10] Young, T.L. (2007) The Handbook of Project Management. 2nd Edition, Kogan Page Limited, London, 26.

[11] Gareis, R. and Huemann, M. (2007) Maturity Models for the Project-Oriented Company. In: Turner, J.R., Ed., Handbook of Project Management, 4th Edition, Gower Publishing Limited, Farnham, 183-208.

[12] Andersen, E.S. and Jessen, S.A. (2003) Project Maturity in Organizations. International Journal of Project Management, 21, 457-461. http://dx.doi.org/10.1016/S0263-7863(02)00088-1

[13] Kerzner, H. (2002) Strategic Planning for Project Management Using a Project Management Maturity Model. John Wiley and Sons, New York. 
[14] Haugan, T.G. (2010) Project Management Fundamentals: Key Concepts and Methodology. 2nd Edition, Management Concepts Inc., Vienna, VA.

[15] Paulk, M.C., Weber, C.V., Curtis, B. and Chrissis, M.B. (1995) The Capability Maturity Model: Guidelines for Improving the Software Process. Addison Wesley, Boston.

[16] PMI (2012) Organizational Project Management Maturity Model (OPM3): Knowledge Foundation. Project Management Institute, Newtown Square.

[17] Shrum, S. and Phillips, M. (2004) CMMI Overview for Executives. Carnegie Mellon University, Software Engineering Institute, Pittsburgh. http://www.dtic.mil/ndia/2004cmmi/CMMIT1WedAM/1295SandyShrum.pdf

[18] Vardakas, E. (2008) Standards and Innovation: Friends or Enemies? Workshop European Standardization and the Greek Reality, Technical Chamber of Greece, Athens. http://portal.tee.gr/portal/page/portal/SCIENTIFIC_WORK/scient_typopoiisi/2008etos/events/praktika.pdf

[19] Lawrence, P.R. and Lorsch, J.W. (1967) Differentiation and Integration in Complex Organizations. Administrative Science Quarterly, 12, 1-47. http://dx.doi.org/10.2307/2391211

[20] European Commission (2012) The Second Economic Adjustment Programme for Greece. Directorate-General for Economic and Financial Affairs, Brussels. http://ec.europa.eu/economy_finance/publications/occasional_paper/2012/pdf/ocp94_en.pdf

[21] Arnaboldi, M., Azzone, G. and Savoldelli, A. (2004) Managing a Public Sector Project: The Case of the Italian Treasury Ministry. International Journal of Project Management, 22, 213-223. http://dx.doi.org/10.1016/S0263-7863(03)00067-X

[22] Kaul, M. and Collins, P. (1995) Governments in Transition: Towards a New Public Administration. Public Administration and Development, 15, 199-206. http://dx.doi.org/10.1002/pad.4230150304

[23] Steers, R.M., Sanchez-Runde, C.J. and Nardon, L. (2010) Management across Cultures: Challenges and Strategies. Cambridge University Press, Cambridge. http://dx.doi.org/10.1017/CBO9780511810510

[24] Koopman, P.L., Hartog, D.N.D. and Konrad, E. (1999) National Culture and Leadership Profiles in Europe: Some Results from the GLOBE Study. European Journal of Work and Organizational Psychology, 8, 503-520. http://dx.doi.org/10.1080/135943299398131

[25] Fitsilis, P., Kirytopoulos, K., Leopoulos, V., Pantouvakis, P. and Saridakis, Y. (2008) Requirements for Assessing the Managerial Capability of Organizations Implementing Projects of Public Interest-The Greek Standard ELOT-1429. PM World Today, Vol. 10, No. 8.

[26] Office of Government Commerce (2010) Introduction and Guide to P3M3. Office of Government Commerce, London. http://www.p3m3-officialsite.com/P3M3Model/Model_mhtry.aspx

[27] PMI (2008) A Guide to the Project Management Body of Knowledge. Project Management Institute, Newtown Square.

[28] IPMA (2008) ICB: IPMA Competence Baseline, Version 4.0., International Project Management Association, Zurich.

[29] Cyprus General Accounting Office (2007) Best Practices Guide for Managing Public Contracts. Cyprus General Accounting Office, Cyprus.

[30] ISO (2003) ISO 10006: 2003 Quality Management Systems—Guidelines for Quality Management in Projects. International Organization for Standardization, Geneva.

[31] New York State Office for Technology (2003) The New York State Project Management Guidebook. 2nd Edition, New York. http://www.cio.ny.gov/pmmp/guidebook2/index.htm

[32] Zafeiris, S. (2005) The Project Owner. Workshop for “Projects of Public Interest”, Technical Chamber of Greece, Athens. http://library.tee.gr/digital/m2073/m2073 zafeiris1.pdf

[33] Pateraki, A. (2007) The Views of Technical Chamber of Greece on Project Management Maturity. Workshop of the Developmental Challenges in the Period 2007-2013 and the Role of the Engineers for the Society of Knowledge, of the Cohesion of Society and the Sustainable Development, Technical Chamber of Greece, Athens. http://library.tee.gr/digital/m2254/m2254_pateraki.pdf

[34] PETA (2008) Research about the Verification of the Project Management Efficiency of LGOs. Information: Training-Local Development (PETA) S.A., Athens. http://www.info-peta.gr

[35] Papadaki, Y. (2008) Improvement of the Management Capability of the LGOs and the Development of the Modern Local Management. Greek Company for Business Administration, Athens. http://www.kedke.gr/?p=540

[36] Cianfrani, C.A., Tsiakals, J.J. and West, J.E. (2009) ISO 9001: 2008 Explained. 3rd Edition, ASQ Quality Press, Milwaukee.

[37] Bolles, D.L. and Hubbard, D.G. (2007) The Power of Enterprise-Wide Project Management. AMAKOM Books, New York. 
[38] Kalofolias, A. (2005) The Education of the Actors of the Public Projects. Workshop for "Projects of Public Interest”, Technical Chamber of Greece, Athens. http://library.tee.gr/digital/m2073/m2073_kalofolias.pdf

[39] IEKEM (2009) Educational Needs of Engineers and of the Executives about IT. Training Institute of Technical Chamber of Greece, Athens. http://library.tee.gr/digital/m2473.pdf

[40] Papatheodorou (2009) The Structural Weaknesses of the Greek Governance and the Challenge of the Greek Project Management Standard. Workshop of The Reform of Public Administration of Greek State, Management Chamber, Athens. http://www.dee.gr/contents.asp?category=34\&id=517

[41] IDeA (2007) Case Study: The First Steps in Implementation of Project Management in Local Authority: Chester City Council. The Improvement and Development Agency (IDeA). http://www.eukn.org/dsresource?objectid=145102

[42] Randhakrishnan, R. and Balasubramanian, S. (2008) Business Process Reengineering. Text and Cases, PHI Learning, New Delhi.

[43] Cobb, C.G. (2011) Making Sense of Agile Project Management: Balancing Control and Agility. John Wiley and Sons, Hoboken. http://dx.doi.org/10.1002/9781118085950

[44] Field, A. (2006) Discovering Statistics Using SPSS. 2nd Edition, Sage Publications, London.

[45] Lepsinger, R. and Lucia, A.D. (2009) The Art and Science of $360^{\circ}$ Feedback. John Wiley and Sons, San Francisco.

[46] Armstrong, M. (2009) Armstrong’s Handbook of Human Resource Management Practice. 11th Edition, Kogan Page Limited, London, 644.

[47] Tullis, T. and Albert, B. (2008) Measuring the User Experience. Elsevier, Amsterdam.

[48] ITA (2005) The Tax Decentralization-Cohesion Fund. Local Governance Institute, Athens. http://www.ita.org.gr/Contents.aspx?lang=gr\&CatId=89\&View $=8$

[49] Greek Official Journal (2003) Law 3230/2004 Establishment of Management System with Goals and Other Provisions. Office of Publications, Athens. http://www.et.gr 
Scientific Research Publishing (SCIRP) is one of the largest Open Access journal publishers. It is currently publishing more than 200 open access, online, peer-reviewed journals covering a wide range of academic disciplines. SCIRP serves the worldwide academic communities and contributes to the progress and application of science with its publication.

Other selected journals from SCIRP are listed as below. Submit your manuscript to us via either submit@scirp.org or Online Submission Portal.
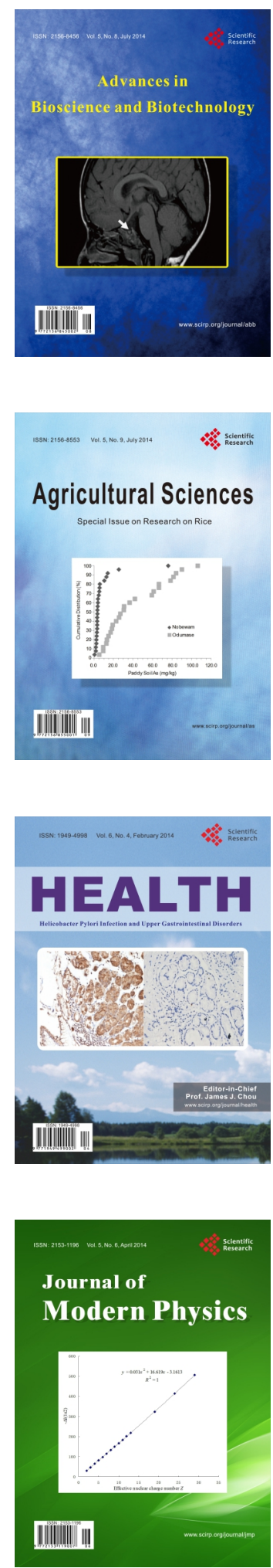
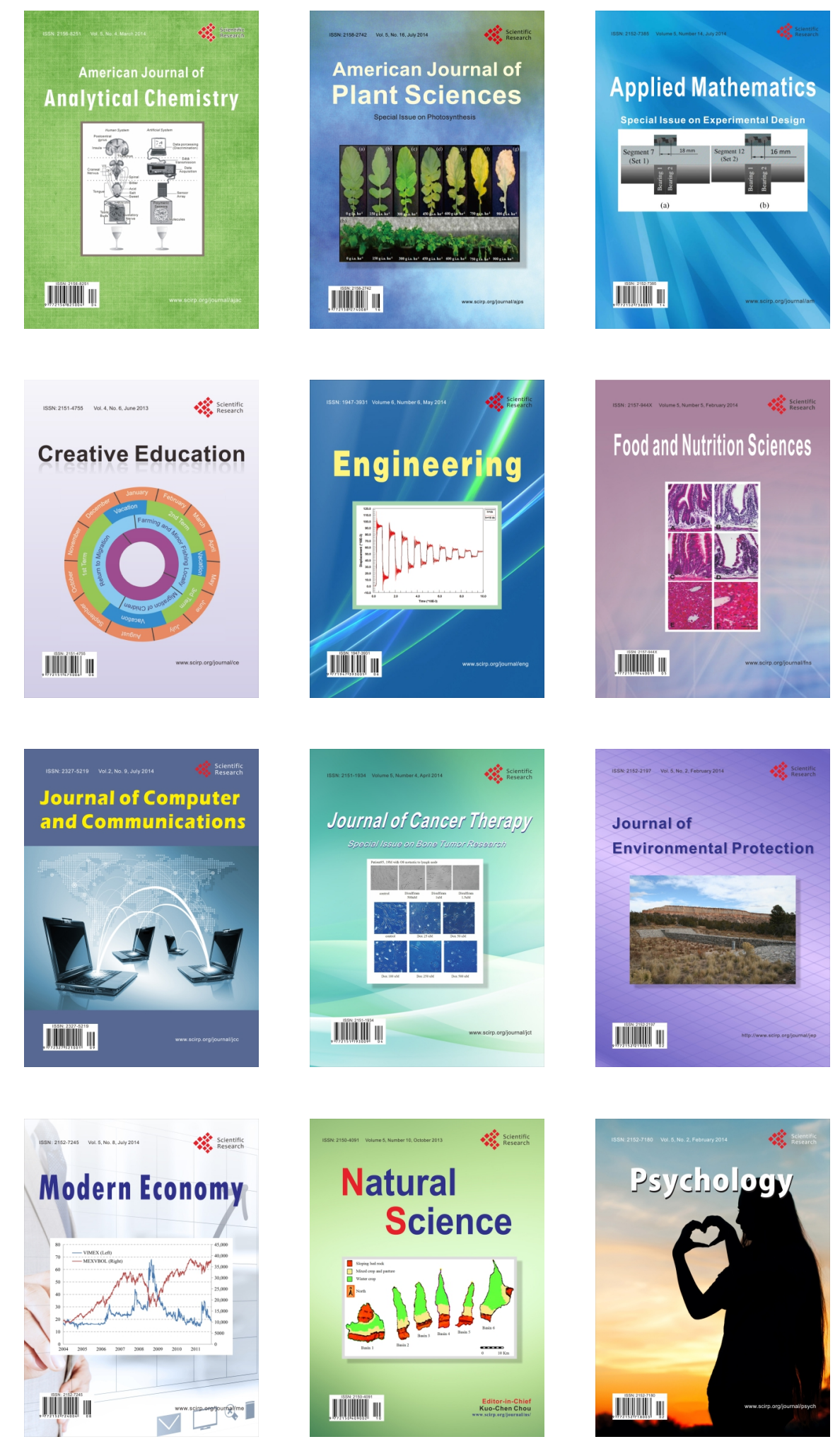